\section{AB0102 IMPAIRMENT OF GRANZYME B-PRODUCING REGULATORY B CELLS EXACERBATED RHEUMATOID ARTHRITIS}

L. Xu, F. Hu, X. Liu, L. Zhu, L. Ren, H. Liu, H. Zhu, Y. Su. Department of Rheumatology and Immunology, Peking University People's Hospital, Beijing, China

Background: Rheumatoid arthritis (RA) is a common and complex autoimmune disease characterized by chronic inflammation and cartilage/bone damage involving numerous cells, such as $\mathrm{T}$ cells, $\mathrm{B}$ cells, chondrocytes, fibroblasts ${ }^{[1]}$. B cells had long been well-demonstrated to participant in the development of RA [2]. Except producing specific antibody and inducing $T$ cell activation, impaired immunosuppressive function of $B$ cells further emphasized their roles in RA recently ${ }^{[3]}$.

Objectives: To investigate whether B cells could produce granzyme B and the potential role in the pathogenesis of Rheumatoid arthritis (RA).

Methods: To reveal the expression of granzyme B in B cells, flow cytometry, PCR and Elispot were performed. The role of IL-21 and anti-BCR stimulation on granzyme $B$ expression was assessed by in vitro stimulation assay. $C D 4^{+} T$ cell-B cell co-culture in the presence of granzyme $B$ neutralizing antibody was performed to demonstrate the function of these cells. Then the levels of granzyme $B$ in $B$ cells between RA patients, OA patients as well as HCs were compared. Next,the correlation analysis between granzyme B-producing B cells and clinical features in RA patients was performed. Finally, the frequencies of granzyme B-producing $B$ cells in RA patients before and after therapy were also evaluated using flow cytometry.

Results: B cells could spontaneously produce granzyme B, which could be perpetuated by IL-21 and anti-BCR stimulation. The frequencies of Th1 and Th17 cells were significantly elevated under the condition of granzyme B blockade when granzyme $B$ was neutralized in $C D 4^{+} T$ cell-B cell co-culture. In RA patients, but not $\mathrm{OA}$ patients and $\mathrm{HCs}$, the frequencies of granzyme-B producing Bregs decreased significantly, which was functionally impaired and negatively correlated with disease activity score 28. Moreover, after effective clinical therapy, the frequencies could recover to nomal levels.

Conclusions: B cells could exert the regulatory functions via granzyme B production. Under RA circumstance, these granzyme B-producing Bregs were impaired and contributed to the disease progression.

\section{References:}

[1] Smolen JS, Aletaha D, McInnes IB, Rheumatoid arthritis, Lancet. 2016 Oct 22;388(10055):2023-2038. doi: 10.1016/S0140-6736(16)30173-8.

[2] Nakken B, Munthe LA, Konttinen YT, et al,B-cells and their targeting in rheumatoid arthritis-current concepts and future perspectives. Autoimmun Rev. 2011 Nov;11(1):28-34. doi: 10.1016/j.autrev.2011.06.010.

[3] Daien Cl, Gailhac S, Mura T, Regulatory B10 cells are decreased in patients with rheumatoid arthritis and are inversely correlated with disease activity. Arthritis Rheumatol. 2014 Aug;66(8):2037-46. doi: 10.1002/art.38666.

Acknowledgements: This study was supported by grants from the Natural Science Foundation of China (81671609, 81671604,31470039).

Disclosure of Interest: None declared

DOI: 10.1136/annrheumdis-2017-eular.2269

\section{AB0103 ANTI-INFLAMMATORY AND IMMUNOMODULATORY EFFECTS BY HUMAN UMBILICAL CORD MESENCHYMAL STEM CELL DERIVED MICROVESICLES IN RATS WITH COLLAGEN INDUCED}

M. Tian, K. Xu, L. Zhang, J. Gao. Rheumatology, Shanxi DaYi Hospital, Shanxi Academy of Medical Sciences, Taiyuan, China

Background: Immunologic deranging and persistent inflammation is closely associated with the arising and developing of rheumatoid arthritis (RA). Increasing investigators demonstrated microvesicles (MVs) derived from mesenchymal stem cell (MSC-MVs) might simulate immune regulation and tissue repair of the parental cells. However,the immunotherapeutic potential of MVs in RA remains unknown.

Objectives: We investigated the therapeutic effects of MSC-MVs in RA model collagen induced arthritis $(\mathrm{CIA})$ rats.

Methods: We tested the therapeutic effects of MSC-MVs on CIA rats,levels of $\mathrm{T}$ helper 17(Th17), regulatory $\mathrm{T}$ cell, and cytokines related, as well as specific transcriptional regulation factor Foxp3 and ROR- $\gamma \mathrm{T}$ analysis was performed.

Results: Here, we show that MSC-MVs administration effectively improve arthritic symptoms, inhibit synovial hyperplasia,thus delaying the progression to inflammatory bone destruction, as effective as their original cells, exerting arthralprotective effects. MSC-MVs treating inhibited the proliferation of $\mathrm{T}$ cell,accelerated the apoptosis. MSC-MVs treating reduce proinflammatory cell Th17, cytokines IL-17, while a incline in the level of an-inflammatory cell Treg,ncytokines TGF- $\beta$. In the spllen and ankle joint of CIA rats, MSC-MVs treating increased the expression level of Foxp3 and coinciding with the ROR- $\gamma$ T suppressed, which, the enhanced therapeutic effects correlated with the increase of dosage in a certain range. Conclusions: MSC-MVs showing anti-inflammatory and immunomodulatory activities on CIA rats, suggesting a new and feasible strategy for protection against RA.

References:

[1] E.M. Gravallese, S.R. Goldring, Cellular mechanisms and the role of cytokines in bone erosions in rheumatoid arthritis, Arthritis Rheum. 43 (10) (2000) 2143-2151.

[2] S. Culshaw, I.B. McInnes, F.Y. Liew, What can the periodontal community learn from the pathophysiology of rheumatoid arthritis? J. Clin. Periodontol. 38(Suppl. 11) (2011) 106-113.

[3] Schett, G., D. Elewaut, I.B. McInnes, J.M. Dayer, and M.F. Neurath, How cytokine networks fuel inflammation: Toward a cytokine-based disease taxonomy. Nat Med, 2013. 19(7): p. 822-4.

Disclosure of Interest: None declared

DOI: 10.1136/annrheumdis-2017-eular.3462

\section{AB0104 ALTERATIONS OF SPLICEOSOME COMPONENTS IN LEUKOCYTES FROM PATIENTS WITH RHEUMATOID ARTHRITIS INFLUENCE THEIR AUTOIMMUNE AND INFLAMMATORY PROFILE, AND THE DEVELOPMENT OF CARDIOVASCULAR DISEASE}

P. Ruiz-Limon ${ }^{1}$, C. Perez-Sanchez ${ }^{1}$, R. Ortega-Castro ${ }^{1}$, S. Pedraza-Arevalo ${ }^{2}$, M. del Rio-Moreno ${ }^{2}$, Y. Jimenez-Gomez ${ }^{1}$, I. Arias de la Rosa ${ }^{1}$,

M. Ábalos-Aguilera ${ }^{1}$, M. Aguirre ${ }^{1}$, P. Segui ${ }^{1}$, E. Collantes ${ }^{1}$, A. Escudero ${ }^{1}$

J. Castaño ${ }^{2}$, R.M. Luque ${ }^{2}$, N. Barbarroja ${ }^{1}$, C. Lopez-Pedrera ${ }^{1} .{ }^{1}$ Rheumatology

Service; ${ }^{2}$ Department of Cell Biology, Physiology, and Immunology, IMIBIC/Reina Sofia Hospital/University of Cordoba, Cordoba, Spain

Background: A significant percentage of genetic and inflammatory diseases derive from splicing alterations. Therefore, the understanding of what modifications in spliceosome determine an alternative splicing and its association with the development of such pathologies is of critical importance.

Objectives: To identify the alterations present in the spliceosome machinery of patients with rheumatoid arthritis (RA),its influence on the development and activity of the disease and their atherothrombotic profile.

Methods: An array of selected components of the major- $(n=12)$ and minorspliceosome $(n=4)$ and associated splicing factors $(n=28)$ was developed, and their expression levels were evaluated using a Fluidigm methodology, in purified leukocytes from 14 RA patients and 14 healthy donors (HD). In parallel, an extensive clinical/serological evaluation was performed. Carotid intimate media thickness (CIMT) was used as atherosclerosis marker. Endothelial activity was monitored by laser-doppler flowmetry, and pro-inflammatory and oxidative stress markers were quantified. Association of these splicing components with clinical and analytical features were investigated.

Results: A significant alteration in various components of spliceosome and splicing factors was found in all the leukocytes subtypes from RA patients vs HD. Interestingly, we found a specific altered profile of splicing factors and spliceosome components when compared monocytes (CA150, PRP8, SRM160, U2AF1, RNU4atac, PTBB1, RAVER1, RBM17, SRSF4, SRSF10), lymphocytes (RNU12, RNU4, RNU6, PRP8, MAGOH, NOVA1, SRSF3) and neutrophils (RNU11, RNU6, SC35, RBM3).

Altered levels of various spliceosome elements in monocytes were associated with the presence of atheromatous plaques, while in neutrophils were found related to radiological involvement. In lymphocytes, the alteration of these components were linked to the positivity for Rheumatoid Factor and anti-CCPs antibodies, indicating that modifications in the spliceosome machinery could contribute to the increase in the production and assembly of autoantigens, inducing autoantibody production.

Correlation studies showed a significant relationship between altered levels of various spliceosome components in different leukocyte subtypes and high disease activity (DAS, HAQ), increased expression of proinflammatory mediators (CRF, TF, TNF, IL-8, TLR4) and oxidative stress markers (peroxides, GPX, SOD) as well as with parameters associated with insulin resistance.

Conclusions: These results reveal that there is a significant alteration of spliceosome components in RA patients that could be associated with the development and activity of this autoimmune condition, and influence mechanisms that drive the development of cardiovascular disease. Studies in progress will help to clarify the physiological implications of these findings, which could constitute new diagnostic biomarkers, as well as new therapeutic tools for the treatment of RA.

Acknowledgements: Funded by CTS7940, and ISCIII (PI15/01333, CP15/00158, and RIER RD16/0012/0015).

Disclosure of Interest: None declared

DOI: 10.1136/annrheumdis-2017-eular.4907

\section{AB0105 DOXYCYCLINE AND DEXAMETHASONE-INDUCED REPROGRAMMING OF PERIPHERAL BLOOD MONONUCLEAR CELLS IN A MODEL OF ARTHRITIS WITH THE SYSTEMIC MANIFESTATIONS IN WISTAR RATS}

P. Litvitskiy ${ }^{1}$, V. Sakharov ${ }^{1}$, E. Alexeeva ${ }^{2}$, N. Mayansky ${ }^{2}$, R. Zakirov ${ }^{2}$ ${ }^{1}$ Pathophysiology, Sechenov First Moscow State Medical University; ${ }^{2}$ Scientific Center of Children's Health, Moscow, Russian Federation

Background: The systemic juvenile idiopathic arthritis (SJIA) is a problem with high social significance all over the world. Targeted cell reprogramming becomes one of the most important lines for modern medicine and can be regarded as 
an origin for new highly improved treatment strategy of sJlA. As rat monocytes exhibited CD163 expression in a similar level with that shown for peritoneal macrophages [1], we decided to use CD163 as a key factor indicating cell reprogramming in the study.

Objectives: To investigate the dynamical changes in subpopulations of peripheral blood mononuclear cells (PBMC) and to assess doxycycline and dexamethasone effects in a model of arthritis with the systemic manifestations.

Methods: Animal model [2] was adapted in 24 Wistar rats (males, 6 month old). On the day of the last stimulation all the rats were divided into 3 equal groups and additional subcutaneous (s.c.) injections were performed as follows: DOXY-group - doxycycline (50 mg/kg, Saratov, Russia), DEXA-group - dexamethasone (4 $\mathrm{mg} / \mathrm{kg}$, KRKA, Slovenia), control group - 0,9\% sodium chloride solution (Belarus). The s.c. injections were repeated on Day 54. Time points were $0,21,41$, and 55 Days. PBMC were assessed by flow cytometry (BD FACSCanto II, USA) according to manufacturer's instructions. Staining was performed with FITC Anti-Rat CD11b (BD Pharmingen), anti-rat CD68 RPE (Serotec, UK), anti-rat CD163 ALEXA FLUOR 647 (Serotec, UK). CD11b+CD68+ and CD11b-CD68+ cells were regarded as monocytes and circulating dendritic cells consequently. At the termination animal organ masses were measured.

Results: Up to Day 55 proportions of $C D 163+$ in $C D 11 b+C D 68+$ population changed synchronically in all groups. On Day 55 the proportions (in comparison with the data of Day 41) were significantly higher in DEXA-group $(p<0,05)$ but didn't change in DOXY- and control groups $(p>0,05)$. Cell reprogramming was also observed in population of CD11b-CD68+. So, on Day 41 the proportions of CD163+ cells in CD11b-CD68+ population were significantly increased (in comparison with the data of Days 0 and 21) in DOXY- and DEXA-groups $(p<0,05)$ but not in control group $(p>0,05)$. Mentioned changes were subsequent with other parameters of inflammation. We observed significantly lower heart masses in DOXY- and DEXA-groups (median $=0,63$ and $0,635 \mathrm{~g}$ consequently) in comparison with control group (median $=0,74 \mathrm{~g})(\mathrm{p}<0,05)$, but no difference between DOXYand DEXA- groups $(p>0,05)$.

Conclusions: In a model of arthritis with the systemic manifestations in Wistar rats we demonstrated that subpopulations of PBMC (CD11b-CD68+ and $\mathrm{CD} 11 \mathrm{~b}+\mathrm{CD68+})$ underwent reprogramming. Doxycycline and dexamethasone modyfied the dynamics of the reprogramming. In DOXY- and DEXA-groups there were lower heart masses than in the control group, the last fact is subsequent with the data by De P. et al. [3]. We can speculate that monocytes and dendritic cells undergo reprogramming (CD163neg and CD163+) in a similar way with M1 and M2 macrophages.

\section{References:}

[1] Moghaddami M, Cleland LG, Mayrhofer G. Int Immunol. 2005; 17(8):1103-15.

[2] Litvitskiy P, Sakharov V, Alexeeva E, et al. Annals of the Rheumatic Diseases. 2016;75:264.

[3] De P, Roy SG, Kar D et al. J Endocrinol. 2011;209(1):105-14.

Disclosure of Interest: None declared

DOI: 10.1136/annrheumdis-2017-eular.3996

\section{AB0106 EFFECT OF SERUM CYTOKINES ON COLLAGEN INDUCED ARTHRITIS RATS AFTER INTRA-ARTICULAR INIECTION OF OZONE}

R. Guo, G. Zhang, L. Zhang, N. Liu. Department of Rheumatology, Shanxi Dayi Hospital, Taiyuan, taiyuan, China

Background: Ozone is a new treatment method, study confirmed that the ozone intra-articular injection can reduce the level of TNFR II CIA in rat synovial TNF-a, synovial tissue, the regulation of rat apoptosis inhibiting gene Bcl-2 decreased expression of proapoptotic gene Bax expression increased, thereby promoting apoptosis of synovial cells. However, there are few reports on the effects of ozone on the inflammatory cytokines such as serum TNF-a in the pathogenesis of RA. Objectives: To observe the effects of intra-articular ozone iniection on the contents of tumor necrosis factor- $\alpha$ (TNF- $\alpha$ ), Interleukin-6 (IL-6), IL-17A, and vascular endothelial growth factor (VEGF)in the serum of rats with collagen-induced arthritis $(\mathrm{CIA})$ and explore the therapeutic mechanism of ozone in RA treatment. Methods: Thrity-two Wistar rats were randomized into 4 groups,including ozone groups receiving intra-articularinjection of $40 \mu \mathrm{g} / \mathrm{ml}$ ozone $\left(\mathrm{O}_{3}\right.$ group), Ca blank control group (normal group), a methotrexate group (MTX group) and a collageninduced arthritismodel (CIA group). All the rats, except for those in the blank control group, were subjected to hypodermic iniection of bovine collagen II and complete Freund'S adiuvant to induce CIA. DOzone treatment was administered once weekly for 3 weeks starting at 14 days after the modeling.MTX group of 0.9 $\mathrm{mg} / \mathrm{kg}$, once a week, a total of three weeks. The swelling degree of the foot were observed,the serum contents of TNF- $\alpha$, IL-6, IL-17A and VEGF were detected. One-way analysis of variance or Kruskal-Wallis test was used to evaluate the experimental data.

Results: At the end of treatment,the foot swelling degree was reduced significantly in rats with $\mathrm{O}_{3}$ group compared with that in the ClA group [4.21 $\pm 0.14 \mathrm{ml}$ and $9.12 \pm 0.17 \mathrm{ml}, \mathrm{t}=8.43, \mathrm{P}=0.023]$. The serum contents of TNF-a, IL-6 and VEGF showed significant difference between the $\mathrm{CIA}$ group and $\mathrm{O}_{3}$ group $[93.86 \pm 12.49$ $\mathrm{pg} / \mathrm{ml}$ and $14.33 \pm 1.85 \mathrm{pg} / \mathrm{ml}, \mathrm{c}^{2}=6.216, P=0.002 ; 189.12 \pm 164.62 \mathrm{pg} / \mathrm{ml}$ and $5.84(5.47,15.93) \mathrm{pg} / \mathrm{ml}, \mathrm{c}^{2}=13.136, P=0.00451 .56(46.09,74.10) \mathrm{pg} / \mathrm{ml}$ and $37.77 \pm 7.88 \mathrm{pg} / \mathrm{ml}, \mathrm{c}^{2}=3.732, \mathrm{CP}=0.002$, there was no statistically significant difference between the $\mathrm{O}_{3}$ group and MTX group $[14.33 \pm 1.85 \mathrm{pg} / \mathrm{ml}$ and 12.45
(11.8.15.6)) pg/ml, $\mathrm{c}^{2}=0.243, P>0.05 ; 5.84(5.47,15.93 \mathrm{pg} / \mathrm{ml}, \mathrm{vs} 9.59 \pm 5.13 \mathrm{pg} / \mathrm{ml}$, $\mathrm{c}^{2}=0.058, P>0.05 ; 37.77 \pm 7.88 \mathrm{pg} / \mathrm{ml}$ and $\left.41.99 \pm 8.78 \mathrm{pg} / \mathrm{ml}, \mathrm{c}^{2}=0.516, P>0.05\right]$. The serum contents of IL-17A showed no significant difference between the normal group, $\mathrm{ClA}$ group,MTX group and the $\mathrm{O}_{3}$ group $(\mathrm{F}=1.827, \mathrm{P}=0.165)$.

\begin{tabular}{c|c|c|c|c}
\multicolumn{5}{|c}{ Comparison of serum levels of inflammatory cytokines in each group } \\
ratsl
\end{tabular}

Note: " indicated that $\mathrm{P}<0.05$ was compared with the control group:

indicated that $\mathrm{P}<0.05$ was compared with CIA group;

Conclusions: Intra-articular iniecfion of $40 \mathrm{ug} / \mathrm{ml}$ ozone Can attenuate svnovitis in rats with $\mathrm{CIA}$, the mechanism of which may involve the inhibition of TNF-a, IL-6 and VEGF in the serum.

References:

[1] Huiqiang Chen,Bin Yu.Efficacy and Mechanism of Using Different Concentrations Ozone to Treat Rheumatoid Arthritis Rats[D]. Southern Medical University, 2011.

[2] Vaillant JD, Fraga A, Díaz MT, et al.Ozone oxidative postconditioning ameliorates joint damage and decreases pro-inflammatory cytokinelevels and oxidative stress in PG/PS-induced arthritis in rats[J]. EurJ Pharmacol 2013;14(1-3):318-324. doi:10.1016/j.ejphar.2013.07.034.

[3] Bocci V, Borrelli E, Travag li V, et al. The ozone paradox: ozone is a strong oxidant as well as a medical drug[J]. Med Res Rev, 2009;29(4):646-682. doi:10.1002/med.20150.

Acknowledgements: Thanks to my tutor, my parterner, and the group medical staff.

Disclosure of Interest: None declared

DOI: 10.1136/annrheumdis-2017-eular.3447

\section{AB0107 THE MODULATION OF MACROPHAGE POLARIZATION BY SIRT1 MAYBE NEW TARGET THERAPY IN RHEUMATOID ARTHRITIS}

$\underline{\text { S.Y. Lee }}^{1}$, S.W. Lee ${ }^{1}$, W.T. Chung ${ }^{1}$, S.Y. Park ${ }^{2}$, J.H. Bae ${ }^{3} \cdot{ }^{1}$ Rheumatology of Internal Medicine, Dong-A University Hospital; ${ }^{2}$ Rheumatology of Internal Medicine; ${ }^{3}$ Biochemistry, Pusan national university, Pusan, Korea, Republic Of

Background: The polarization of macrophages was the expressed to M1/M2 phenotype by various stimuli or environment signals. The M1 macrophage was pro-inflammatory phenotype and was key effector cells in the immune response of rheumatoid arthritis (RA). So, M1 macrophage influenced the inflammation of RA synovial membrane and joint destruction in RA, whereas M2 macrophage was anti-inflammatory phenotype and could down-regulate the production of proinflammatory cytokines in RA. The SIRT1 attenuated the RA inflammation via down-regulation of NF-кB signaling. However, the effect of SIRT1 on macrophages polarization remained uncler.

Objectives: We aimed to check out that activated SIRT1 modulated macrophages polarization into M1 phenotype and controlled the inflammation of RA.

Methods: Monocytes from synovial fluid of RA patients, bone marrow-derived monocytes (BMDCs) from mice were studied. monocytes were cultured with M-CSF for 7days to differentiate into M0 macrophages (monocyte-derived mature macrophages M0 phenotype). M0 macrophages were incubated with LPS and IFN-gamma in order to obtain M1 macrophages. M1 macrophage markers were detected by real-time PCR.

Results: Activation of SIRT1 was achieved by Resveratrol, activated SIRT1 attenuated M1 macrophage phenotypes and pro-inflammatory cytokine expression. macrophages obtained from SIRT1-tg mice, which were overexpression of SIRT1, exhibited decreased M1 markers in association with enhanced activation of AMPK/ACC compared with macrophage from control C57BL/6 mice. In addition to SIRT1 activation, M1 polarizing signal, acetylation of NF-kB p65, was suppressed. In SIRT1-deficient macrophages, resveratrol fail to increase AMPK activity and to decrease the expression M1 markers owing to enhanced acetylation of NF- $\kappa B$ p65.

Conclusions: SIRT1 maybe an important modulator of M1 macrophages polarization and increased AMPK activity, which suppressed acetylation of NF-kB p65 during inflammation of RA. so, modulation of SIRT1 maybe a new target in RA treatment.

\section{References:}

[1] SIRT1 inhibits differentiation of monocytes to macrophages: amelioration of synovial inflammation in rheumatoid arthritis. J Mol Med (Berl). 2016 Aug;94(8):921-31. 